\title{
Altered glycosylation in tumours focused to cancer diagnosis
}

\author{
Rosa Peracaula ${ }^{\mathrm{a}, *}$, Sílvia Barrabés ${ }^{\mathrm{a}}$, Ariadna Sarrats $^{\mathrm{a}}$, Pauline M. Rudd $^{\mathrm{b}}$ and Rafael de Llorens ${ }^{\mathrm{a}}$ \\ ${ }^{a}$ Unitat de Bioquímica i Biologia Molecular, Departament de Biologia, Universitat de Girona, Campus de \\ Montilivi s/n, Girona, Spain \\ ${ }^{\mathrm{b}}$ Dublin-Oxford Glycobiology Laboratory, NIBRT, Conway Institute, University College Dublin, Belfield, Dublin, \\ Ireland
}

\begin{abstract}
The lack of specific and sensitive tumour markers for early detection of cancer is driving a search for new approaches that could identify biomarkers. Markers are needed to alert clinicians at the early stages of tumourogenesis, before the cancer has metastasized, when the therapeutic drugs are more effective. Most tumour markers currently used in clinics are serum glycoproteins, frequently highly glycosylated mucins. Typically, the disease marker is the protein and not the glycan moiety of the corresponding glycoprotein or mucin. The increasing knowledge of the role of glycans in cancer suggests that further studies may assist both in determining their role in every step of tumour progression, and in the design of new therapeutic and diagnosic approaches. Detection of the altered glycans in serum tumour glycoproteins could be a way to achieve specificity in tumour detection. In this review, we focus on the glycan changes of two serum glycoproteins, prostate specific antigen - currently used as a tumour marker of prostate cancer - and human pancreatic ribonuclease in pancreatic adenocarcinoma. The detection of glycan changes, associated with subsets of glycoforms in serum glycoproteins that are specific to the tumour situation, could be the basis for developing more specific biomarkers.
\end{abstract}

Keywords: Glycosylation, tumour markers, prostate specific antigen, human pancreatic ribonuclease

\section{Introduction}

Cancer is rapidly becoming one of the most important health issues in the developed world, causing devastating effects on patients and their families as much as in terms of economic costs of its treatment and loss of human capital. Since 2005 it has become the leading cause of death in USA and showing the same tendency in other industrialized countries [1]. Recent cancer statistics $[2,3]$ indicate that the likelihood of developing cancer is approximately one in two for men and one in three for women. Survival patient rates for the most common cancers - as lung, prostate, breast and colorectal - remain very low. Five year survival varies

* Corresponding author: Unitat de Bioquímica i Biologia Molecular, Departament de Biologia, Universitat de Girona, Campus de Montilivi s/n, 17071 Girona, Spain. Fax: +34 972418150; E-mail: rosa.peracaula@udg.es. greatly according to the cancer site and state at diagnosis, but there is always a decrease of survival with more advanced disease, which points out to the importance of screening and early detection. Most people have advanced disease at the time of diagnosis, and this reduces drastically their survival times. Survival rates for people diagnosed with advanced cancer have changed little over the past 20 years, with a few notable exceptions (childhood cancers, and cancer of the testis), whereas the death rates for cardiac, cerebrovascular and infectious diseases have declined by about two-thirds. The percentages of survival range from $5 \%$ and $10 \%$, in metastatic advanced lung and colorectal cancers compared with the $50-90 \%$ when the cancer is localized, which illustrates the poor survival of patients with advanced cancer [4]. By contrast, survival is relatively good when cancers are diagnosed at an early stage, because established treatments can be applied early when they are more effective [5]. 
The question that arises is whether very early detection and diagnosis of tumours is possible.

\section{Tumour markers}

Early diagnosis of cancer is difficult because of the lack of specific symptoms in early disease. The value of early detection of cervical cancer was established in 1950 thanks to Papanicolau's smear test. Since then, some tumour markers have been introduced (Table 1), but without generally desirable results.

Tumour markers have been defined as molecules produced by the cancer cells, or induced by the cancer on normal cells, that are present in biological material that can be obtained from the patient, and reflect malignant activity [6]. Recently, the concept of tumour marker has been expanded to what has been called "Biomarker". Several definitions of Biomarker have been established:

- A quantifiable measurement of biological "normality" providing a reference for detecting abnormal situations [7-9].

- Measurable phenotypic parameter that characterizes an organism's state of health or disease, or a response to a particular therapeutic intervention [9].

According to the National Institutes of Health, a Biomarker is a characteristic that is objectively measured and evaluated as an indicator of normal biologic processes, pathogenic processes, or pharmaceutical responses to a therapeutic intervention [10]. The concept of Biomarker includes physiological status, images, specific molecules, genetic alterations, and genetic and protein expression profiles. Accordingly, they have been classified as DNA based markers, RNA based markers, Protein markers - including carbohydrate determinants and blood peptidome [11], and molecular imaging [12].

In fact, early detection in cancer still remains a problem [4], it is the so-called poor relation of cancer research. Early detection studies face different challenges: discovery, development and evaluation, or validation of the probe. No single biomarker can detect a tumour with $100 \%$ sensitivity (all patients are detected) and specificity (healthy people are not detected), necessary conditions for a general and adequate population mass screening. Biomarkers should have the potential to be used clinically to screen for, diagnose, or monitor the activity of diseases and to guide molecular targeted therapy or assess therapeutic response.
The current trend is a panel or set of different markers with their own sensitivity and specificity $[13,14]$. Optimally, the scientific research community is attempting to find biomarkers to identify the different types of cancer and the steps of the malignant progression, in order that therapy can be optimised for each patient at every moment. This panel should enhance the positive predictive value of a test and minimise the proportion of false positive and false negative results.

Currently new technologies are being introduced modern spectrometers, genomics, metabolomics, proteomics and other "omics" technologies such as "glycomics", and new powerful imaging technologies, based on isotope labelled specific peptides. These new advances are expected to identify and establish a set of Biomarkers, including the detection of early signs [15]. Although these various "omics" technologies are promising, the fact is that they have not yet produced widely applicable new approaches to detection and patient therapy, and none of the biomarkers currently used by clinicians were discovered through the new high-throughput genomic or proteomic technologies.

This review is focused on the "classic" concept of tumour marker as a single molecular entity that could still be useful. In fact, tumour markers of this type are the only ones used in current clinical setting. In particular, we will focus on targeted glycoproteomics, and more specifically on the glycosylation of specific serum proteins, because most tumour markers are glycoproteins, frequently highly glycosylated mucins (Table 1). In addition, we expect many proteins secreted by the tumour to carry tumour-related glycans that may distinguish them from the same proteins secreted from healthy cells.

From the main tumour markers included in this table, we would like to highlight the ones that correspond to glycoproteins like human chorionic gonadotropin$\beta$ (hCG- $\beta$ ) prostate specific antigen (PSA), alphafetoprotein (AFP), carcinoembryonic antigen (CEA), epidermal growth factor receptor 2 (ErbB-2) and highly glycosylated mucins like CA 19.9, CA 125, CA 27.29, CA 15.3 , which remarkably are the most used in current clinical practice.

\subsection{Tumour marker glycoproteins:}

- Human chorionic gonadotropin- $\beta$ (hCG- $\beta$ ): This is a glycoprotein normally produced by the placenta. High levels in serum are associated with pregnancy, trophoblastic disease and nonseminomatous germ tumours [13]. 
Table 1

Most used human tumour markers in clinical practice. Extracted and modified from [6,13,15]

\begin{tabular}{|c|c|c|c|}
\hline Tumour marker & structure & Ref. levels & pathologies \\
\hline AFP. $\alpha$-fetoprotein & $\begin{array}{l}\text { Glycoprotein, with high homology to } \\
\text { albumin }\end{array}$ & $<10 \mathrm{ng} / \mathrm{ml}$ & $\begin{array}{l}\text { hepatocellular adenocarcinoma, } \\
\text { tumours of testis and ovary. }\end{array}$ \\
\hline $\begin{array}{l}\beta \text { HCG. } \\
\text { Human chorionic gonadotropin }\end{array}$ & $\begin{array}{l}\beta \text { Fraction of the chorionic } \\
\text { gonadotropin }\end{array}$ & $<2 \mathrm{U} / \mathrm{ml}$ & $\begin{array}{l}\text { Trophoblastics tumours, germinal neo- } \\
\text { plasias of the testis and ovary. }\end{array}$ \\
\hline $\begin{array}{l}\text { Cancer antigen } \\
\text { CA } 15-3\end{array}$ & $\begin{array}{l}\text { Mucin identified by monoclonal } \\
\text { antibodies }\end{array}$ & $<35 \mathrm{U} / \mathrm{ml}$ & Breast and ovary adenocarcinomas \\
\hline $\begin{array}{l}\text { Cancer antigen } \\
\text { CA 19-9 }\end{array}$ & $\begin{array}{l}\text { Glycolipid with the blood group anti- } \\
\text { gen Lewis a }\end{array}$ & $<37 \mathrm{U} / \mathrm{ml}$ & $\begin{array}{l}\text { Gastrointestinal carcinomas, especially } \\
\text { pancreas. }\end{array}$ \\
\hline $\begin{array}{l}\text { Cancer antigen } \\
\text { CA } 125\end{array}$ & $\begin{array}{l}\text { Mucin identified by monoclonal } \\
\text { antibodies }\end{array}$ & $<35 \mathrm{U} / \mathrm{ml}$ & $\begin{array}{l}\text { Lung, ovary and endometrial } \\
\text { adenocarcinomas. }\end{array}$ \\
\hline $\begin{array}{l}\text { Cancer antigen } \\
\text { CA } 549\end{array}$ & $\begin{array}{l}\text { Mucin identified by monoclonal } \\
\text { antibodies }\end{array}$ & $<13 \mathrm{U} / \mathrm{ml}$ & Breast and ovary adenocarcinomas \\
\hline $\begin{array}{l}\text { Cancer antigen } \\
\text { CA } 27-29\end{array}$ & $\begin{array}{l}\text { Mucin identified by monoclonal } \\
\text { antibodies }\end{array}$ & $<38 \mathrm{U} / \mathrm{ml}$ & Breast cancer \\
\hline $\begin{array}{l}\text { CEA. } \\
\text { Carcinoembrionary antigen }\end{array}$ & Glycoprotein family & $<5 \mathrm{ng} / \mathrm{ml}$ & Epithelial neoplasias \\
\hline ErbB-2 / HER-2 & $\begin{array}{l}\text { Glycoprotein. Tyrosine-kinase recep- } \\
\text { tor of the EGF family. }\end{array}$ & $<15 \mathrm{U} / \mathrm{ml}$ & Breast cancer \\
\hline MCA. Antigen associate to mucins & $\begin{array}{l}\text { Mucin identified by monoclonal } \\
\text { antibodies }\end{array}$ & $<13 \mathrm{U} / \mathrm{ml}$ & Breast and ovarian cancer \\
\hline $\begin{array}{l}\text { PAP. Placental alkaline } \\
\text { phosphatase. }\end{array}$ & $\begin{array}{l}\text { Thermostable alkalyne phosphatase } \\
\text { Isoenzyme }\end{array}$ & $>100 \mathrm{U} / \mathrm{L}$ & $\begin{array}{l}\text { Testicular seminomas and ovarian } \\
\text { cancer }\end{array}$ \\
\hline PSA. Prostate specific antigen & $\begin{array}{l}\text { Glycoprotein. Serine-protease of the } \\
\text { kallykrein family. }\end{array}$ & $4-10 \mathrm{ng} / \mathrm{ml}$ & Prostate cancer \\
\hline $\begin{array}{l}\text { SCC. Associate antigen of the } \\
\text { escamous carcinomas }\end{array}$ & $\begin{array}{l}\text { Glycoprotein. Fraction of the antigen } \\
\text { T4. }\end{array}$ & $<2.5 \mathrm{ng} / \mathrm{ml}$ & Epidermoid carcinomas \\
\hline TAG 72 Mucin & $\begin{array}{l}\text { Glycoprotein identified by monoclonal } \\
\text { antibodies }\end{array}$ & $<6 \mathrm{U} / \mathrm{ml}$ & $\begin{array}{l}\text { Lung, ovarian and gastrointestinal } \\
\text { carcinomas }\end{array}$ \\
\hline TG. Thyroidal glycoprotein & $\begin{array}{l}\text { Glycoproteic hormone synthesized by } \\
\text { the follicular cells of thyroids. }\end{array}$ & $<27 \mathrm{ng} / \mathrm{ml}$ & $\begin{array}{l}\text { Follicular and papillary neoplasias of } \\
\text { thyroids }\end{array}$ \\
\hline
\end{tabular}

- Alpha-Fetoprotein (AFP): the first "Oncofetal Antigen" described that received the name of Alpha-Fetoprotein. It is a glycoprotein present in foetal serum and related to albumin. AFP is associated with hepatocellular carcinoma and nonseminomatous germ cell tumours [13]. The proportion of sialylated glycoforms of AFP changes between hepatocarcinoma and other benign liver diseases, which also show elevated AFP serum levels. The specific detection of the sialylated AFP related to hepatocarcinoma could be used to increase specificity [16].

- Carcinoembryonic antigen (CEA): an oncofetal glycoprotein normally present in the membranes of mucosal cells and overexpressed in adenocarcinomas, especially colorectal cancer.

- Prostate Specific Antigen (PSA): a glycoprotein of the kallikrein protease family (Human Kallikrein 3) mostly produced by the prostate. Its serum levels in healthy men are very low, but they increase in prostate pathologies, like benign prostate hyperplasia, prostatitis, and especially prostate cancer. PSA has been used extensively for prostate cancer screening. It is the most widely used tumour marker in clinical practice, but its utility in identifying patients at increased risk of prostate cancer remains controversial.

- ErbB-2: glycoprotein of the Epidermal Growth Factor Receptor family, in fact a tyrosine kinase. It is overexpressed in several malignancies, especially in breast cancer. It is also a therapeutic target using monoclonal antibodies and using inhibitors against its tyrosine kinase activity.

\subsection{Tumour marker glycosylated mucins:}

These tumour markers correspond to epitopes of highly glycosylated mucins detected by specific monoclonal antibodies.

- Cancer Antigen 125 (CA-125): a glycosylated mucin present in foetal development. Elevated serum CA-125 values are most often associated with epithelial ovarian cancer.

- Cancer Antigen 19-9 (CA 19-9): Corresponds to a carbohydrate structure found either in gangliosides or mucins that contain the sialyl-Lewis A antigen [17]. It is present primarily in pancreatic 
and biliary tract cancers, but also in patients with other malignancies and benign conditions such as cirrhosis and pancreatitis.

- Cancer Antigen 27-29 (CA 27-29): a specific epitope of the glycoprotein Mucin-1, that is present on the apical surface of normal epithelial cells. It is highly associated with breast cancer, although elevated levels are also due to several other malignancies, and benign disorders of the breast, liver and kidney.

- CA15.3: this is a serum mucin-like glycoprotein. It is associated with breast cancer and some benign gastrointestinal diseases. Combined with CEA, it raises the specificity for breast cancer up to $95 \%$.

As shown above, the list of biomarkers in clinical practice reveals that many of them are glycoproteins, including glycosylated mucins and carbohydrate antigens. Considering that in tumour situation cancer cells use non-normal or "aberrant" glycosylation for their particular functions such as escaping from the immune attack, attaching to capillary endothelia during invasion and establishing new adhesions for metastasis, the determination of the glycosylation status can be an important approach for detecting non-normal or pathological situations.

This "aberrant" glycosylation can be detected in blood substances, and in the last few years it has also been described in secreted proteins present in serum such as AFP [16], PSA [18-20], human pancreatic ribonuclease 1 [21,22] or alpha-1-acid glycoprotein [23]. Therefore, there is a renewed interest in this research area. "Glycomics" is becoming and important "omic" field, already present in the scientific literature as a promising tool for the discovery of new and more specific biomarkers [24,25].

\section{Glycans in cancer}

Glycan alteration is a common feature in tumour cells and may affect any type of cell glycoconjugate such as N-glycans and O-glycans on glycoproteins, glycolipids or glycosaminoglycans [26,27 and references cited herein].

Several alterations have been reported and implicate the under or over expression of certain glycan structures and the presentation of other glycan structures normally restricted to embryonic developmental cells. For instance, an increase in the branching of N-glycans, a general augmentation in sialic acid content, an over- expression of specific carbohydrate antigens that lead to terminal structures like sialyl-Lewis ${ }^{\mathrm{x}}\left(\mathrm{SLe}^{\mathrm{x}}\right)$, sialylLewis $^{\mathrm{a}}\left(\mathrm{SLe}^{\mathrm{a}}\right)$, or polysialic acid are often associated to tumour cells (Fig. 1). The expression of some of those glycan structures can be correlated to the malignant phenotype of tumour cells. For instance, those pancreatic adenocarcinoma cell lines that overexpress $\mathrm{SLe}^{\mathrm{x}}$ and SLe ${ }^{\mathrm{a}}$ have higher metastatic potential that the same cells where the expression of these antigens have been inhibited [28,29].

Glycans are involved in processes of cell adhesion and motility and regulate cell-cell and cell-extracellular matrix communication. Therefore, cell glycan expression is crucial in several steps of tumour progression where those processes are involved, such as detachment from the extracellular matrix, cell motility for invasion, adhesion to activated endothelial cells or metastasis. Some of the glycan changes reported in tumour cells have been demonstrated to assist tumour development in some of these key steps that increase their malignant potential [30 and references cited herein].

Alteration of glycosylation can be found either in the glycocalyx of the tumour cells or in particular glycoproteins that play important roles in the tumorigenic process. As an example of the first, the overexpression of $\mathrm{SLe}^{\mathrm{x}}$ in several adenocarcinomas has been related to an increase of the invasive and metastatic potential of the tumours. SLe ${ }^{\mathrm{x}}$ acts as a ligand of $\mathrm{E}$ and P-selectins and mediates the first adhesion step of the tumor cells to the activated endothelium, before the extravasation step [31]. The malignant phenotype of the $\mathrm{SLe}^{\mathrm{x}}$ expressing tumour cells has been obstructed by either blocking the attachment of SLe ${ }^{\mathrm{x}}$ to the activated endothelium using metabolic decoys that act as competitors of the molecule [32,33] or by reverting the biosynthesis to more fucosylated antigens like $\mathrm{Le}^{\mathrm{y}}$ [28]. As an example of the second, specific glycosylation changes, such as an increase of the N-glycan branching, in key receptor proteins like the Epidermal Growth Factor Receptor (EGFR), have been shown to activate their signalling pathway by reducing the turnover rates and maintaining the receptors for longer on the cell membrane [34]. In particular, the formation of tetra-antennary structures by action of the MGAT5 enzyme (GlcNAcT-V) promotes the activation of EGFR signalling pathways, leading to cell growth and division. On the contrary, diminishing the EGFR Nglycan branching, caused by GlcNAcT-V, reduces the invasiveness and metastatic potential of tumour cells by decreasing the EGF mediated activation of the SHP-2 tyrosine phosphatase, and in consequence inhibits the 

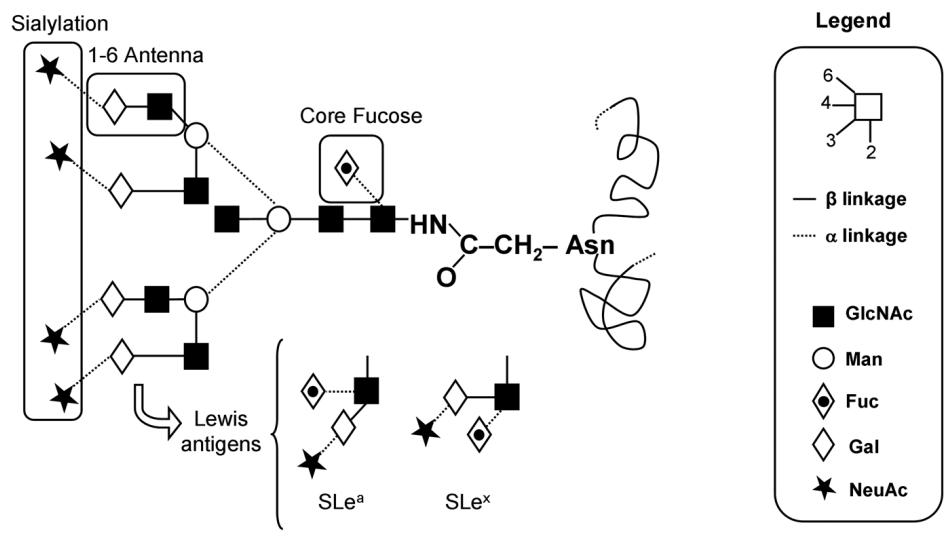

Fig. 1. Example of a N-glycan structure containing some of the main carbohydrate alterations found in tumours: $\beta$-1,6-branching, sialylation, core fucosylation and sialyl-Lewis antigens.

dephosphorylation of the focal adhesion kinase (FAK), reducing cell motility and tumour invasiveness [35].

Some of the mechanisms that lead to these glycan alterations are related to changes in the glycosylation machinery of tumour cells. Glycosyltransferases and glycosidases levels in the secretory pathway can be altered and therefore affect the glycan structures synthesized by the cell [36]. Considering that in the secretory pathway several glycosyltransferases can compete for the same substrates, changes in their concentration can alter the final proportion of the glycoforms of a particular glycoprotein or glycolipid. Thus, changes in the expression of specific glycosyltransferases like MGAT-5, which is responsible for the $\beta 1-6 \mathrm{GlcNAc}$ branching, or in specific sialyltransferases and fucosyltransferases involved in the biosynthesis of sialyl-Lewis antigens have been correlated to the expression of some tumour glycan structures [28,37], which promote the invasive and metastatic abilities of tumour cells. As mentioned above, the inhibition of GlcNAcT-V expression in the metatastic breast carcinoma cells MDA-MB231 causes their malignant phenotype to revert [35]. This enzyme could thus be considered a good target for the development of specific inhibitors that could have therapeutic potential.

Whether these reported changes in the glycosylation of tumour cells are a cause or a result of the tumorigenic process is still unknown. In this context, it has to be kept in mind that some of the glycosylation changes reported in tumour cells are not only specific of the tumour situation. Many inflammatory processes can involve similar changes in cell glycosylation. For instance, $\mathrm{SLe}^{\mathrm{x}}$ and 6-sulpho-SLe ${ }^{\mathrm{x}}$ are up-regulated in the endothelium of chronically inflamed tissues, and their expression favours the homing of lymphocytes to those tissues [38].
The microenvironment that surrounds tumour cells has to be taken into account to understand the glycosylation changes in tumour cells. Inflammation is a key mediator in many cancers. In pancreatic adenocarcinoma, inflammatory pathways create an environment that supports tumour formation [39]. Several cytokines released in inflammatory processes, like IL- $1 \beta$, TNF- $\alpha$ and IL- 6 , could be some of the factors that lead to an alteration in the expression level of the tumour cell glycosyltransferases and therefore changes in the tumour cell glycosylation. It has been described that IL- $1 \beta$, when supplied to hepatocarcinoma cells, induces the expression of SLe ${ }^{\mathrm{x}}$ through an enhanced expression of the sialyltransferase ST3Gal IV and the fucosyltransferase FUT VI [40].

The increasing knowledge of the alterations of tumour glycan processing pathways and the mechanisms that lead to these changes is currently being exploited for therapeutic and/or diagnosis purposes.

From the diagnostic point of view, some of the glycoconjugates released by the tumour cells can be measured in the blood stream and can be used as tumour markers of specific cancers as well as markers that can help to monitoring the evolution of the tumour in response to therapy. It is the case of CA19.9, CA125, CA15.3, CA27-29, all mucins with a high content of glycans indicative of a tumour situation. However, their lack of specificity, as described above, suggests the need for the development of more targeted strategies. In this regard, one approach is to focus on the glycan moiety of specific proteins secreted by the tumour, which could carry altered glycans due to the changes in the glycosylation machinery of the tumour cells. The detection of these specific glycoforms of the protein secreted by the tumour, in a targeted way, could be helpful to improve diagnosis of a specific cancer (Fig. 2). 

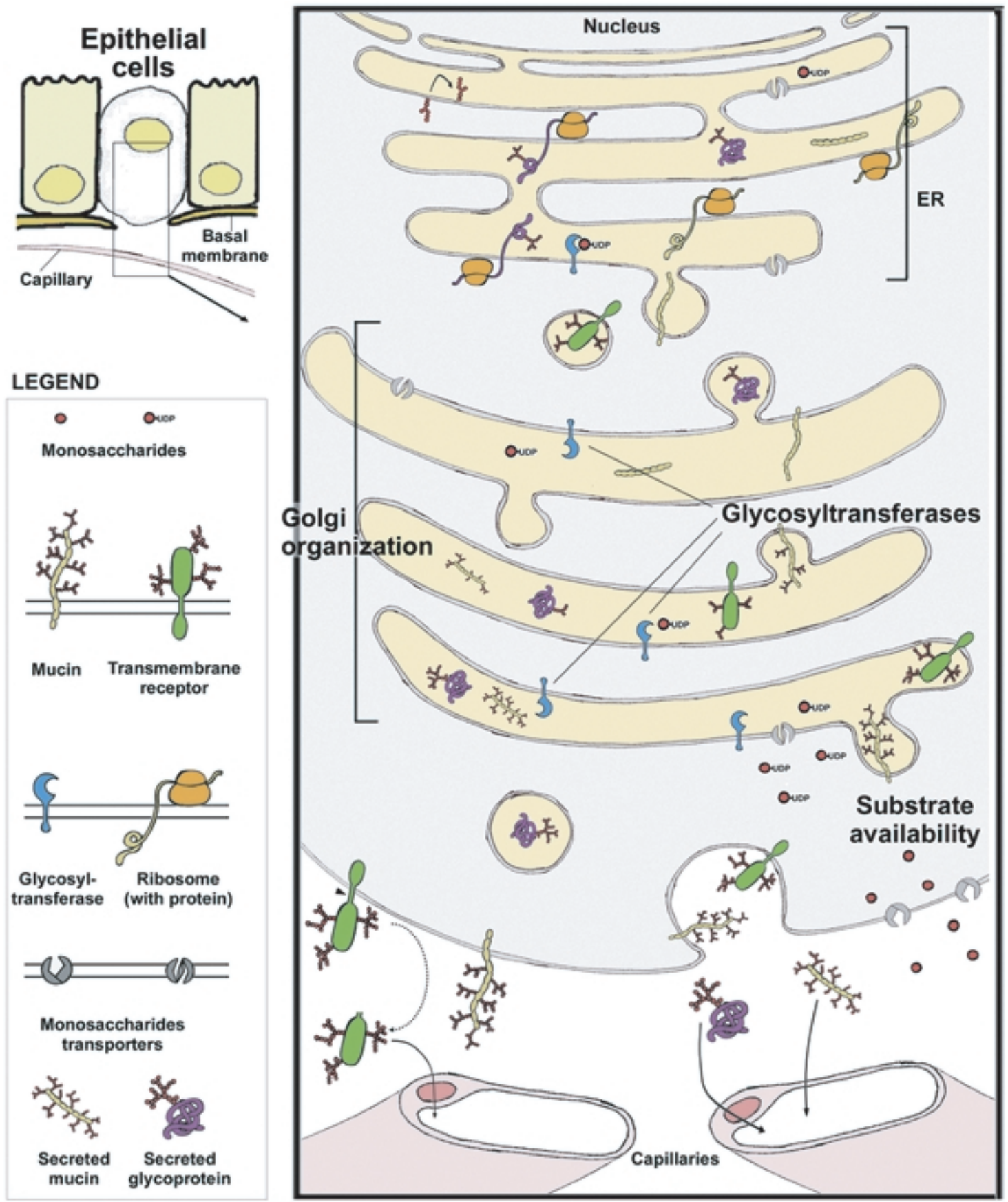

Fig. 2. Schematic drawing showing the main sites where the glycosylation of secreted proteins, membrane proteins and mucins can be altered during the secretory pathway, such as modification in the expression levels of glycosyltransferases, in the availability of sugar-donours and changes in the Golgi organization. In the upper left corner, disruption of the basal membrane and loss of normal topology and polarization of epithelial cells in cancer results in the release of the glycoproteins and mucins into the bloodstream. The detection of the altered glycosylation of these serum proteins could assist in the developing of tumour markers.

In this respect we have focused on the analysis of the specific glycoforms of the prostate specific antigen, PSA, which is released from the prostate cells into the serum during prostate pathological states, including prostate cancer. The detection of specific glycoforms of PSA tumour-related could help to improve the 
specificity in the diagnosis of prostate cancer.

\section{PSA glycosylation in cancer}

Prostate specific antigen (PSA) is a $28 \mathrm{kDa}$ glycoprotein comprising 237 amino acid residues with a single N-linked glycosylation site at Asn45. It belongs to the human kallikrein family (human kallikrein 3), and exhibits serine-protease activity [41]. It is produced as a proenzyme by the prostate epithelial cells and secreted into the lumen of the prostate gland where it is activated. The prostate glands are surrounded by a continuous layer of basal cells and a basement membrane, which may be disrupted by a prostate disease. Thus, PSA can access the peripheral circulation and be detected in blood [42]. This process characterises not only prostate cancer (PCa) but also other prostate benign diseases such as benign prostate hyperplasia (BPH) and prostatitis [43].

The predominant molecular PSA form present in blood is the complex of PSA with protease inhibitors, mainly alpha-1-antichymotrypsin (ACT) [42]. The rest of the PSA is inactive and circulates as free PSA. This includes proPSA forms, internally nicked PSA forms such as BPSA and not nicked but inactive PSA forms (iPSA) [44].

In 1994 the U.S Food and Drug Administration approved the PSA test as an aid to early detection of $\mathrm{PCa}$, using a threshold of $4 \mathrm{ng} / \mathrm{mL}$, as a result of the study by Catalona et al., 1991 [45]. This study reported a 22\% incidence rate of prostate cancer when serum PSA levels were between 4 and $10 \mathrm{ng} / \mathrm{mL}$. This rate increased to $67 \%$ when serum PSA levels were higher than 10 $\mathrm{ng} / \mathrm{mL}$. However, there is an appreciable risk of false positives when using the $4 \mathrm{ng} / \mathrm{mL}$ threshold, resulting in unnecessary biopsies for those with BPH. Furthermore, recent studies point out an important rate of $\mathrm{PCa}$ when serum PSA levels are lower thant $4 \mathrm{ng} / \mathrm{mL}: 6.6 \%$ (0-0.5 ng/mL), $10.1 \%(0.6-1 \mathrm{ng} / \mathrm{mL}), 17.0 \%$ (1.1-2 $\mathrm{ng} / \mathrm{mL}), 26.9 \%(3.1-4 \mathrm{ng} / \mathrm{mL})$; suggesting an insufficiency of the $4 \mathrm{ng} / \mathrm{mL}$ threshold [46].

There have been several attempts to improve PSA specificity, mostly based on the measure of complex PSA [47], free PSA [48] and specific free PSA forms such as proPSA [49] and BPSA [50] but also on its possibly altered glycosylation.

PSA N-linked glycans from seminal plasma have been described as partially sialylated complex-type biantennary structures, mostly core ( $\alpha$ 1-6)-fucosylated; with a minor percentage of GalNAc terminated anten- nae [18,51]. Detailed glycan analysis of PSA from healthy and malign origins has shown significant differences. When comparing PSA from seminal plasma (healthy donor) and PSA secreted by the tumour prostate cell line LNCaP, a loss of sialylation could be detected for LNCaP PSA oligosaccharides, which were all neutral and contained a higher fucose and $\mathrm{N}$ acetylgalactosamine content $[18,19]$. The comparison of the glycosylation pattern between PSA from seminal plasma (healthy donor) and PSA from PCa patient's serum showed a decrease in the fucose and alpha2,3linked sialic acid content for the PSA from a PCa patient's serum.

Other approaches have been done to study PSA altered glycosylation, particularly using lectins binding capacity. In Basu et al., 2003 [52], Concavalin A was used to study general glycosylation of PSA from PCa and BPH patient's sera. According to this study, PSA from PCa patient's sera showed less general glycosylation than that of BPH patient's sera. Ohyama et al., 2004 [53] reported an increased Maackia amurensis agglutinin (MAA)-bound fraction in free PSA from PCa patient's sera compared to that of BPH patient's sera. MAA lectin specifically recognizes alpha2,3linked sialic acid. Consequently, alpha2,3-linked sialic acid content was increased in free PSA PCa patient's sera compared to free PSA BPH patient's sera.

Most of these studies showed a modification of the sialylation pattern of PSA. Sialic acid is a negatively charged carbohydrate and the increased or decreased sialic acid content can modify the PSA theoretical isoelectric point (pI). Two-dimensional electrophoresis (2DE) has been used to study PSA forms of different sources as it allows separating them not only according to their molecular weight, but also to their pI [20, 54-56]. When PSA is separated in a 2-DE gel, 5 main forms at approximately $33 \mathrm{kDa}$ are observed (Fig. 3). We will refer to them as F1, F2, F3, F4 and F5 (from the lowest to the highest pI). The PSA forms were partially characterized using glycosidase enzymes and the data suggest that F1, F2 and F3 contain sialic acid while F4 and F5 may not [19].

Jung et al., 2004 [56] studied free PSA forms obtained after 2-DE from $\mathrm{PCa}$ and $\mathrm{BPH}$ patients sera and reported significant differences in F3 and F4 percentages between the two groups of samples. The percentages of F3 and F4 were directly opposite in BPH and PCa patients. F3 was lower in BPH patients (median: 23\%; range: $3-68 \%$ ) than $\mathrm{PCa}$ (median: $49 \%$, range: $15-86 \%$ ), whereas $\mathrm{F} 4$ was higher in $\mathrm{BPH}$ patients (median: $73 \%$, range: $2-99 \%$ ) than in PCa patients (median: $45 \%$, range: $14-77 \%)$. 


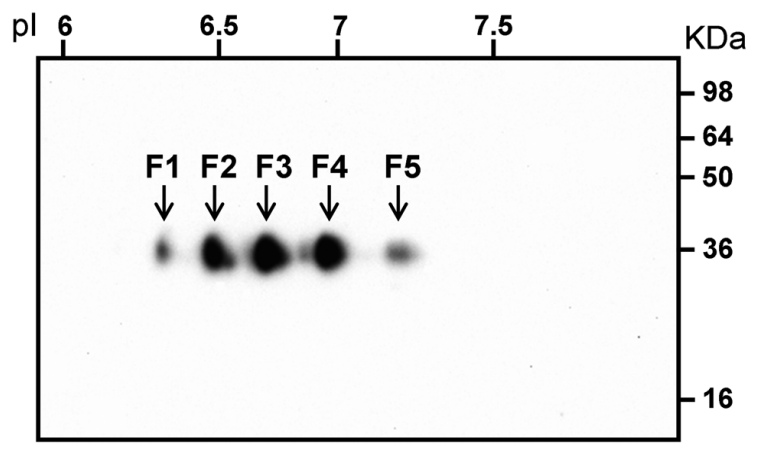

Fig. 3. 2-Dimensional Electrophoresis and Western blot of total serum PSA from a prostate cancer patient. Detection by chemiluminescence. Molecular mass in $\mathrm{kDa}$ on the right, isoelectric points $(\mathrm{pI})$ at the top. Five different PSA forms F1, F2, F3 F4 and F5 can be detected.

All serum PSA studies using 2-DE have focused on free PSA, which represents only $10-30 \%$ of total serum PSA. Serum can be treated to release complex PSA [57], so that total PSA can then be analysed by 2-DE. In our laboratory, we performed this procedure before the PSA 2-DE analysis of 20 PCa patients' sera and $20 \mathrm{BPH}$ patients' sera (total PSA levels: 2.04$71.62 \mathrm{ng} / \mathrm{mL}$ ). F3 was significantly higher in BPH patients than PCa patients. Significant differences were also found when excluding patients with serum PSA levels higher than $20 \mathrm{ng} / \mathrm{mL}$ from the statistical analysis. PCa patients were divided according to their stage (localized, locally advanced and metastatic). The higher the stage of the PCa the lower F3, showing a negative statistical correlation [58]. The change in F3 and F4 proportions compared with the ones reported by Jung et al., 2004 [56] may be due to the pre-treatment of the serum samples to analyse total PSA.

The differences in PSA glycosylation from benign and malign prostate pathologies reported by different studies show that these can be used to improve PSA specificity, especially concerning the degree of sialylation. However, further investigations are required to fully characterise F3 and F4, which seem to be promising tools for distinguishing between PCa and BPH.

In a similar way, as described for PSA and prostate cancer, we have focused on the analysis of the glycoforms of a protein mainly secreted by the pancreas (human pancreatic ribonuclease 1 or RNase 1), which historically had been associated with pancreatic cancer, to identify altered glycoforms in the protein in pancreatic cancer sera that could help to pancreatic cancer diagnosis.

\section{RNAse 1 glycosylation in cancer}

RNase 1 is a glycoprotein with three $\mathrm{N}$-glycosylation sites that is present in serum and many other organs and body fluids [59-61]. There are several studies describing RNase 1 as a possible tumour marker for pancreatic cancer $[62,63]$, given that this organ was thought to be the main producer of serum RNase 1 for many years. However, further studies showed that neither the RNase 1 levels nor the RNase 1 activity in serum are specific or sensitive enough as a pancreatic cancer marker $[64,65]$. Pancreatic adenocarcinoma is one of the cancers with higher mortality and worse prognosis [66] and lacks the specific and sensitive markers for its early diagnosis, that are required to improve the survival rate. Currently several efforts are aimed to find biomarkers for this type of neoplasia [67].

Alterations in the cell glycoconjugates is a common feature of cancer transformation. Therefore modifications in the glycosylation of RNase 1 associated with pancreatic cancer have been analysed in order to find out whether an aberrantly serum glycosylated RNase 1 could be of diagnostic utility [21,22]. Glycan structures of RNase 1 obtained from healthy pancreas and RNase 1 produced by several pancreatic cancer cell lines appeared to be different. Glycan structures of RNase 1 from healthy pancreas were all neutral while RNase 1 from pancreatic cancer cell lines contained sialylated structures [21]. The study of the differences in the glycosylation of serum RNase 1 from two control patients and two pancreatic cancer patients also showed differences between the two groups related to the fucosylated RNase 1 glycoforms. In pancreatic cancer sera, RNase 1 shows an increase of $40 \%$ in core fucosylation in relation to RNase 1 from healthy controls [22].

Glycan structures of serum RNase 1 were different from those previously described for RNase 1 from a healthy pancreas or from the conditioned media of pancreatic carcinoma cell lines. However, they matched with those found in RNase 1 from the conditioned media of endothelial cell lines [22], which produce significant quantities of RNase 1 [68]. Actually, the reported similarities in glycan structures from serum and endothelial RNase 1 strongly suggest that the main origin of serum RNase 1 is the endothelium rather than the pancreas (Fig. 4).

Serum RNase 1 , mainly produced by the endothelium, presents changes in its glycan structures in pancreatic cancer patients, in particular the increase in the proportion of biantennary core fucosylated structures. This suggests that cancer situation is inducing changes 


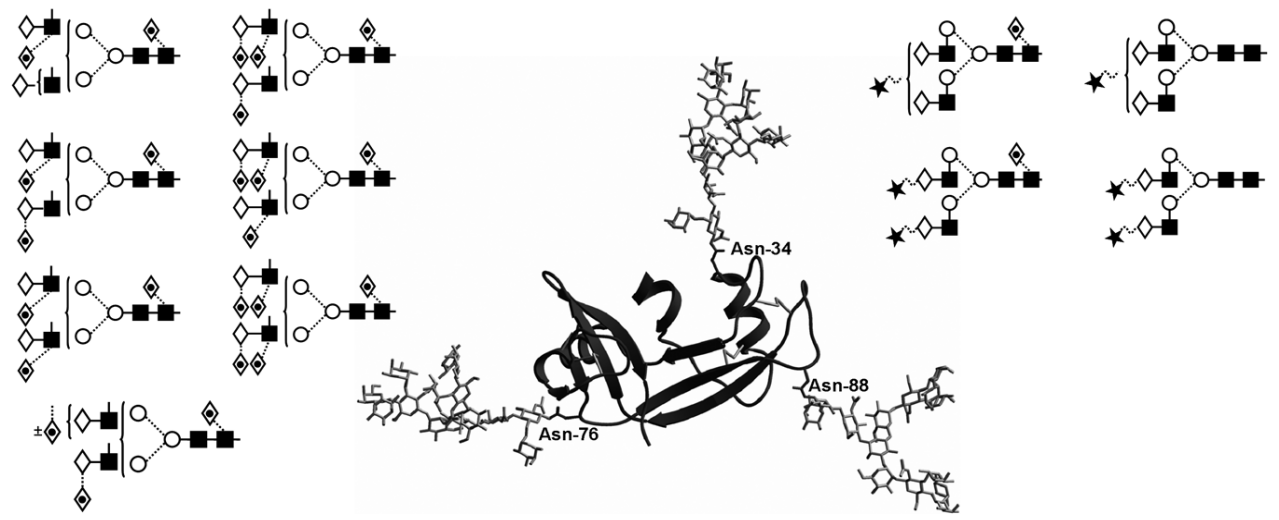

Main RNase 1 glycan structures - Serum

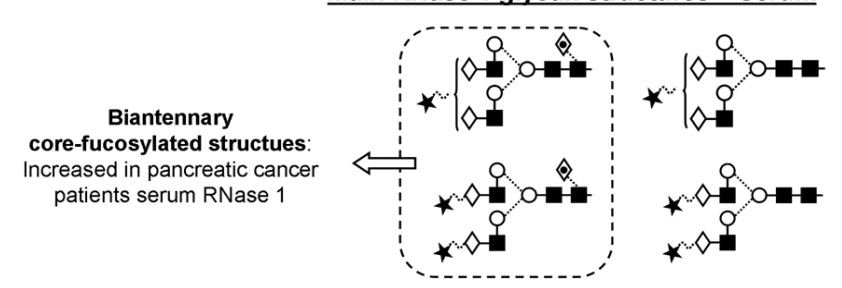

Fig. 4. In the centre, modelling of the highly fucosylated complex biantennary glycan chains of RNase 1 from pancreas on the three dimensional structure of RNase $1 \Delta$ N7. The authors acknowledge the modelling to Wormald MR, Dwek RA and Rudd PM of the Oxford Glycobiology Institute. Main glycan structures found in RNase 1 from pancreas, endothelial cell lines and serum are shown.

in the glycosylation pathways of the endothelial cells. The way that these glycan changes are generated is still unknown and is of a major interest. Inflammation occurring during tumour processes could explain cell glycosylation changes. During the inflammatory processes, several molecules such as cytokines are released, which affect not only the immune system but also the surrounding cells and tissues. For instance, some cytokines, like TNF- $\alpha$, have been reported to regulate the glycosylation pathways in inflammatory bowel diseases and also in colon cancer [69]. The alterations of the glycosylation machinery observed in hepatocellular carcinoma, such as the ones that lead to an increase of AFP core fucosylation, are the same ones described for chronic inflammation of the liver [70].

On the other hand, tumour cells may also release some inflammatory factors, which could induce alterations in the glycosylation machinery of other neighbouring cells. In pancreatic cancer, serum haptoglobin, a protein secreted by the liver, is more core fucosylated than in serum from healthy controls and other patients suffering from different malignancies, suggesting an influence of the pancreatic cancer cells on the glycosylation pathways of the neighbouring hepatic cells [71]. Thus, the alteration in the molecules of the surrounding tissues induced by the presence of the tumour can also be a potential source of new biomarkers.

Glycosylation can be a valuable tool for cancer detection. Searching for glycosylation changes in specific proteins in the sera of tumour patients, in what has been called targeted glycoproteomics, seems to be a promising approach to discover new biomarkers. In particular, these new potential biomarkers could be valuable when used in combination with traditional tumour markers and other diagnostic approaches, especially for the early detection of many different tumours for which specific and sensitive biomarkers are still not available.

\section{Acknowledgements}

A.S. gratefully acknowledges Universitat de Girona for a pre-doctoral fellowship. This work was supported by the Department of Science and Technology from the Ministerio de Educación y Ciencia (grants BIO 20040438 and BIO 2007-61323) and by the Foundation $L a$ Marató de TV3 (grant 050932) awarded to R.P. and the Government of Catalonia (grant 2005-SGR00065) awarded to R.L. 


\section{Abbreviations}

ACT: alpha-1-antichymotrypsin

AFP: alpha-fetoprotein

$\mathrm{BPH}$ : benign prostate hyperplasia

CEA: carcinoembryonic antigen

2-DE: Two-dimensional electrophoresis

EGFR: epidermal growth factor receptor

ErbB-2: epidermal growth factor receptor 2

hCG- $\beta$ : human chorionic gonadotropin- $\beta$

IL: interleukin

iPSA: inactive PSA

Le $^{\mathrm{y}}$ : Lewis ${ }^{\mathrm{y}}$

MAA: Maackia amurensis agglutinin

PCa: prostate cancer

pI: isoelectric point

PSA: prostate specific antigen

RNase 1: human pancreatic ribonuclease 1

SLe $^{\mathrm{a}}$ : sialyl-Lewis ${ }^{\mathrm{a}}$

SLe $^{\mathrm{x}}$ : sialyl-Lewis ${ }^{\mathrm{x}}$

TNF- $\alpha$ :tumour necrosis factor alpha

\section{References}

[1] L. Spinney, Caught in time, Nature 442 (2006), 736-738.

[2] M.J. Hayat, N. Howlader, M.E. Reichman and B.K. Edwards, Cancer Statistics, Trends, and Multiple Cancer Analyses from the Surveillance, Epidemiology, and End Results (SEER) Program, Oncologist 12 (2007), 20-37.

[3] A. Jemal, R. Siegel, E. Ward, T. Murray, J. Xu, and M.J Thun, Cancer Statistics, 2007, CA Cancer J Clin, 57 (2007), 43-66.

[4] R. Etzioni, N. Urban, S. Ramsey, M. McIntosh, S. Schwartz, B. Reid, J. Radich, G. Anderson and L. Hartwell, The Case for Early Detection, Nat Rev Cancer 3 (2003), 1-10.

[5] H. Varmus, The New Era in Cancer Research, Science 312 (2006), 1162-1165.

[6] R. Molina and X. Filella, Marcadores Tumorales, Estado Actual Y Perspectivas de Futuro II, Ed., Roche Diagnostics SL. Lab Diagnostics, Spain, 2003.

[7] W.S. Dalton and S.H. Friend, Cancer Biomarkers - An Invitation to the Table, Science 312 (2006), 1165-1168.

[8] P.R. Srinivas, B.S. Kramer and S. Srivastava, Trends in Biomarker Research for Cancer Detection, Lancet Oncol 2 (2001), 698-704.

[9] R.S. Negm, M. Verma and S. Srivastava, The Promise of Biomarkers in Cancer Screening and Detection, Trends Mol Med 8 (2002), 288-293.

[10] K. Bensalah, F. Montorsi and SF. Shariat, Challenges of Cancer Biomarker Profiling, Eur Urol 52 (2007), 1601-1609.

[11] E.F. Petricoin, C. Belluco, R.P. Araujo and LA. Liotta, The blood peptidome: A higher dimension of information content for cancer biomarker discovery, Nat Rev Cancer 6 (2006), 961-967.

[12] S.M. Okarvi, Peptide-based radiopharmaceutical and cytotoxic conjugates: Potential tools against cancer, Cancer Treat Rev 34 (2008), 13-26.
[13] GL. Perkins, ED. Slater and GK. Sanders, Serum Tumor Markers, Am Fam Physician 68 (2003), 1075-1082.

[14] S.F. Shariat, J.A. Karam, V. Margulis and P.I. Karakiewicz, New blood-based biomarkers for the diagnosis, staging and prognosis of prostate cancer, BJU Int 101 (2008), 675-683.

[15] J.A. Ludwig and J.N. Weinstein, Biomarkers in Cancer Staging, Prognosis and Treatment Selection, Nat Rev Cancer 5 (2005), 845-856.

[16] T.C. Poon, T.S. Mok, A.T. Chan, C.M. Chan, V. Leong, S.H. Tsui, T.W. Leung, H.T. Wong, S.K. Ho and P.J. Johnson, Quantification and utility of monosialylated alpha-fetoprotein in the diagnosis of hepatocellular carcinoma with nondiagnostic serum total alpha-fetoprotein, Clin Chem 48 (2002), 1021-1027.

[17] K.S. Goonetilleke and A.K. Siriwardena, Systematic review of carbohydrate antigen (CA19.9) as a biochemical marker in the diagnosis of pancreatic cancer, EJSO 33 (2007), 266-270.

[18] R. Peracaula, G. Tabares, L.Royle, D.J. Harvey, R.A Dwek, P.M Rudd and R. de Llorens, Altered glycosylation pattern allows the distinction between prostate-specific antigen (PSA) from normal and tumor origins, Glycobiology 13 (2003), 457470 .

[19] G. Tabares, C.M. Radcliffe, S. Barrabes, M. Ramirez, R.N. Aleixandre, W. Hoesel, R.A. Dwek, P.M. Rudd, R. Peracaula and R. de Llorens, Different glycan structures in prostatespecific antigen from prostate cancer sera in relation to seminal plasma PSA, Glycobiology 16 (2006), 132-145.

[20] G. Tabares, K. Jung, J. Reiche, C. Stephan, M. Lein, R. Peracaula, R. de Llorens and W. Hoesel, Free PSA forms in prostatic tissue and sera of prostate cancer patients: Analysis by 2-DE and western blotting of immunopurified samples, Clin Biochem 40 (2007), 343-350.

[21] R. Peracaula, L. Royle, G. Tabares, G. Mallorqui-Fernández, S. Barrabés, D.J. Harvey, R.A. Dwek, P.M. Rudd, and R.de Llorens, Glycosylation of human pancreatic ribonuclease: Differences between normal and tumor states, Glycobiology 13 (2003), 227-244.

[22] S. Barrabés, L.Pagès-Pons, C.Radcliffe, G. Tabares, E. Fort, L. Royle, D. Harvey; M. Moenner, R.A Dwek, P.M.Rudd, R. de Llorens and R. Peracaula, Glycosylation of serum ribonuclease 1 indicates a major endothelial origin and reveals an increase in core fucosylation in pancreatic cancer, Glycobiology 17 (2007), 388-400.

[23] R. Saldova, L. Royle, C.M. Radcliffe, U.M. Abd Hamid, R. Evans, J.N. Arnold, R.E. Banks, R. Hutson, D.J. Harvey, R. Antrobus, S.M. Petrescu, R.A. Dwek and P.M. Rudd, Ovarian Cancer is Associated with Changes in Glycosylation in Both Acute-Phase Proteins and IgG, Glycobiology 17 (2007), 13441356.

[24] G. Durand and N. Seta, Protein glycosylation and diseases: Blood and urinary oligosaccharides as markers for diagnosis and therapeutic monitoring, Clin Chem 46 (2000), 795-805.

[25] P.M. Rudd and R.A. Dwek, Structural Glycobiology in Medicine. Carbohydrates and Glycoconjugates, Curr Opinion in Struct Biol 16 (2006), 559-560.

[26] R. Peracaula, Altered glycosylation in tumour proteins: Biological implications, Afinidad 64 (2007), 346-355.

[27] D.H. Dube and C.R. Bertozzi, Glycans in cancer and inflammation-potential for therapeutics and diagnostics, Nat Rev Drug Discov 4 (2005), 477-488.

[28] M. Aubert, L. Panicot, C. Crotte, P. Gibier, D. Lombardo, MO. Sadoulet and E. Mas, Restoration of $\alpha(1,2)$ fucosyltransferase activity decreases adhesive and metastatic properties of human pancreatic cancer cells, Cancer Res 60 (2000), 1449-1456. 
[29] M. Aubert, L. Panicot-Dubois, C. Crotte, V. Sbarra, D. Lombardo, MO. Sadoulet and E. Mas, Peritoneal colonization by human pancreatic cells is inhibited by antisense FUT3 sequence, Int J Cancer 88 (2000), 558-565.

[30] M.M. Fuster and J.D. Esko, The sweet and sour of cancer: Glycans as novel therapeutic targets, Nat Rev Cancer 5 (2005), 526-542.

[31] R. Kannagi, Molecular mechanism for cancer-associated induction of sialyl Lewis $\mathrm{X}$ and sialyl Lewis A expression-The Warburg effect revisited. Glycoconj J 20 (2004), 353-364.

[32] J.L. Magnani, The discovery, biology, and drug development of sialyl Lea and sialyl Lex, Arch Biochem Biophys 426 (2004), $122-131$.

[33] P. Nangia-Makker, J. Conklin, V. Hogan and A. Raz, Carbohydrate-binding proteins in cancer, and their ligands as therapeutic agents, Trends Mol Med 8 (2002), 187-192.

[34] E.A. Partridge, C. Le Roy, G.M. Di Guglielmo, J. Pawling, P. Cheung, M. Granovsky, I.R. Nabi, J.L. Wrana and J.W. Dennis, Regulation of cytokine receptors by Golgi N-glycan processing and endocytosis, Science 306 (2004), 120-124.

[35] H.B. Guo, M. Randolph and M. Pierce, Inhibition of a specific N-glycosylation activity results in attenuation of breast carcinoma cell invasiveness-related phenotypes: Inhibition of epidermal growth factor-induced dephosphorylation of focal adhesion kinase, J Biol Chem 282 (2007), 22150-22162.

[36] K. Ohtsubo and J.D. Marth, Glycosylation in cellular mechanisms of health and disease, Cell 126 (2006), 855-867.

[37] R. Peracaula, G. Tabarés, A. López-Ferrer, R. Brossmer, C. de Bolós, and R. de Llorens, Role of sialyltransferases involved in the biosynthesis of Lewis antigens in human pancreàtic tumour cells, Glycoconj J 22 (2005), 135-144.

[38] J. Renkonen, O. Tynninen, P. Hayry, T. Paavonen and R. Renkonen, Glycosylation might provide endothelial zip codes for organ-specific leukocyte traffic into inflammatory sites, $\mathrm{Am}$ J Pathol 161 (2002), 543-550.

[39] B. Buckminster Farrow and M. Evers, Inflammation and the development of pancreatic cancer, Surgical Oncology 10 (2002), 153-169.

[40] K. Higai, N. Miyakazi, Y. Azuma and K.Matsumoto, Interleukin-1 $\beta$ induces sialyl Lewis $\mathrm{X}$ on hepatocellular carcinoma HuH-7 cells via enhanced expression of ST3Gal IV and FUT VI gene, FEBS Letters 580 (2006), 6069-6075.

[41] A.M. Ward, J.W Catto and F.C. Hamdy, Prostate specific antigen: Biology, biochemistry and available commercial assays, Ann Clin Biochem 38 (2001), 633-651.

[42] S.P.Balk, Y.J. Ko and G.J. Bubley, Biology of prostate-specific antigen, J Clin Oncol 21 (2003), 383-391.

[43] S. Bracarda, O. de Cobelli, C. Greco, T. Prayer-Galetti, R. Valdagni, G. Gatta, F. de Braud, and G. Bartsch, Cancer of the prostate, Crit Rev Oncol Hematol 56 (2005), 379-396.

[44] S.D. Mikolajczyk, L.S. Marks, A.W. Partin and H.G. Rittenhouse, Free prostate-specific antigen in serum is becoming more complex, Urology 59 (2002), 797-802.

[45] W.J. Catalona, D.S. Smith, T.L. Ratliff, K.M. Dodds, D.E. Coplen, J.J. Yuan, J.A. Petros, and G.L. Andriole, Measurement of prostate-specific antigen in serum as a screening test for prostate cancer. $N$ Engl J Med 324 (1991), 1156-1161.

[46] I.M. Thompson, D.K. Pauler, P.J. Goodman, C.M. Tangen, M.S. Lucia, H.L Parnes, L.M Minasian, L.G. Ford, S.M. Lippman, E.D. Crawford, J.J Crowley and C.A. Jr. Coltman, Prevalence of prostate cancer among men with a prostate-specific antigen level $<$ or $=4.0 \mathrm{ng}$ per millilitre, $N$ Engl J Med $\mathbf{3 5 0}$ (2004), 2239-2246.
[47] M.K. Brawer, G.E. Meyer, J.L. Letran, D.D. Bankson, D.L. Morris, K.K. Yeung and W.J. Allard, Measurement of complexed PSA improves specificity for early detection of prostate cancer, Urology 52 (1998), 372-378.

[48] W.J. Catalona, P.C. Southwick, K.M. Slawin, A.W.Partin, M.K. Brawer, R.C. Flanigan, A. Patel, J.P. Richie, P.C. Walsh, P.T. Scardino, P.H. Lange, G.H. Gasior, K.G. Loveland and K.R. Bray, Comparison of percent free PSA, PSA density, and age-specific PSA cutoffs for prostate cancer detection and staging, Urology 56 (2000), 255-260.

[49] S.D. Mikolajczyk, W.J. Catalona, C.L. Evans, H.J. Linton, L.S. Millar, K.M. Marker, D. Katir, A. Amirkhan and H.G. Rittenhouse, Proenzyme forms of prostate-specific antigen in serum improve the detection of prostate cancer, Clin Chem $\mathbf{5 0}$ (2004), 1017-1025.

[50] H.J. Linton, L.S. Marks, L.S. Millar, C.L. Knott, H.G Rittenhouse and S.D. Mikolajczyk, Benign prostate-specific antigen (BPSA) in serum is increased in benign prostate disease, Clin Chem 49 (2003), 253-259.

[51] T. Okada, Y.Sato, N. Kobayashi, K. Sumida, S. Satomura, S. Matsuura, M. Takasaki and T. Endo, Structural characteristics of the N-glycans of two isoforms of prostate-specific antigens purified from human seminal fluid, Biochim Biophys Acta 1525 (2001), 149-160.

[52] P.S. Basu, R. Majhi and S.K. Batabyal, Lectin and serumPSA interaction as a screening test for prostate cancer, Clin Biochem 36 (2003), 373-376.

[53] C. Ohyama, M. Hosono, K. Nitta, M. Oh-eda, K. Yoshikawa, T. Habuchi, Y. Arai and M. Fukuda, Carbohydrate structure and differential binding of prostate specific antigen to Maackia amurensis lectin between prostate cancer and benign prostate hypertrophy, Glycobiology 14 (2004), 671-679.

[54] J.P. Charrier, C. Tournel, S. Michel, P. Dalbon, and M. Jolivet, Two-dimensional electrophoresis of prostate-specific antigen in sera of men with prostate cancer or benign prostate hyperplasia, Electrophoresis 20 (1999), 1075-1081.

[55] T. Isono, T. Tanaka, S. Kageyama, and T. Yoshiki, Structural diversity of cancer-related and non-cancer-related prostatespecific antigen, Clin Chem 48 (2002), 2187-2194.

[56] K. Jung, J. Reiche, A. Boehme, C. Stephan, S.A. Loening, D. Schnorr, W. Hoesel, and P. Sinha, Analysis of subforms of free prostate-specific antigen in serum by two-dimensional gel electrophoresis: Potential to improve diagnosis of prostate cancer, Clin Chem 50 (2004), 2292-2301.

[57] J. Peter, C. Unverzagt and W. Hoesel, Analysis of free prostatespecific antigen (PSA) after chemical release from the complex with alpha(1)-antichymotrypsin (PSA-ACT), Clin Chem 46 (2000), 474-482.

[58] A. Sarrats, Analysis of the Serum Prostate Specific Antigen (PSA) forms to Improve the Prostate Cancer Diagnosis, Master Thesis, University of Girona, 2007.

[59] J. Weickmann and D. Glitz, Human ribonucleases: Quantitation of pancreatic-like enzimes in serum, urine and organ preparation, J Biol Chem 257 (1982), 8705-8710.

[60] J. Futami, Y. Tsushima, Y. Murato, H. Tada, J. Sasaki, M. Seno and $\mathrm{H}$. Yamada, Tissue-specific expression of pancreatic-type Rnases and Rnase inhibitors in humans, DNA Cell Biol 16 (1997), 413-419.

[61] E. Fernández-Salas, R. Peracaula, M. Frazier and R. de Llorens, Ribonucleases expressed by human pancreatic adenocarcinoma cell lines, Eur J Biochem 267 (2000), 1484-1494.

[62] K. Reddi and J. Holland, Elevated serum ribonuclease in patients with pancreatic cancer, Proc Natl Acad Sci 73 (1976), 2308-2310. 
[63] D. Maor and M.J. Mardiney, Alteration of human serum ribonuclease activity in malignancy, CRC. Crit Rev Clin Lab Sci 10 (1978), 89-111.

[64] J. Weickmann, E. Olson and D. Glitz, Immunological assay of pancreatic ribonuclease in serum as an indicator of pancreatic cancer, Cancer Res 44 (1984), 1682-1687.

[65] M. Kurihara, M. Ogawa, T. Ohta, E. Kurokawa, T. Kitahara, K. Matsuda, G. Kosaki, T. Watanabe and H. Wada, Radioimmunoassay for human pancreatic ribonuclease and measurement of serum immunoreative pancreatic ribonuclease in patients with malignant tumors, Cancer Res 44 (1984), 2240 2243.

[66] J. Ferlay, P. Autier, M. Boniol, M. Heanue, M. Colombet and P. Boyle, Estimates of the cancer incidence and mortality in Europe in 2006, Ann Oncol 18 (2007), 581-592.

[67] T. Grote and C. Logsdon, Progress on molecular markers of pancreatic cancer, Curr Opin Gastroenterol 23 (2007), 508518.

[68] J. Landré, P. Hewett, J. Olivot, P. Friedl, Y. Ko, A. Sachinidis and M. Moenner, Human endothelial cells selectively express large amounts of pancreatic-type ribonuclease (RNase 1), $J$ Cell Biochem 86 (2002), 540-552.

[69] B.J. Campbell, L-G. Yu and J. M. Rhodes, Altered glycosylation in inflammatory bowel disease: A possible role in cancer development, Glycoconj J 18 (2001), 851-858.

[70] K. Moriwaki, K Noda, T. Nakagawa, M. Asahi, H. Yoshihara, N. Taniguchi, N. Hayashi and E. Miyoshi, A high expression of GDP-fucose transporter in hepatocellular carcinoma is a key factor for increases in fucosylation, Glycobiology 17 (2007), 1311-1320.

[71] N. Okuyama, Y. Ide, M. Nakano, T. Nakagawa, K. Yamanaka, K. Moriwaki, K. Murata, H. Ohigashi, S. Yokoyama, H. Eguchi, O. Ishikawa, T. Ito, M. Kato, A. Kasahara, S. Kawano, J. Gu, N. Taniguchi and E. Miyoshi, Fucosylated haptoglobin is a novel marker for pancreatic cancer: A detailed analysis of the oligosaccharide structure and a possible mechanism for fucosylation, Int J Cancer 118 (2006), 2803-2808. 


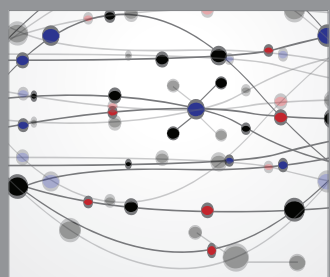

The Scientific World Journal
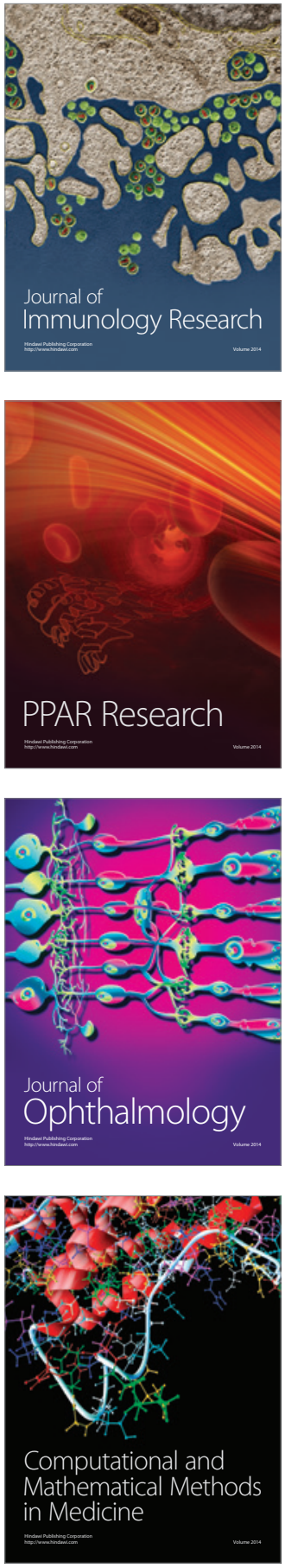

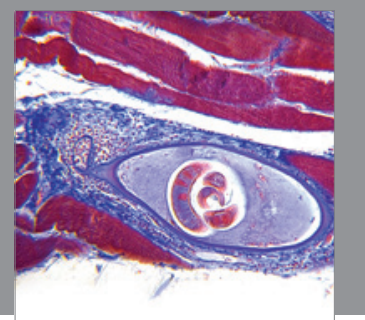

Gastroenterology

Research and Practice
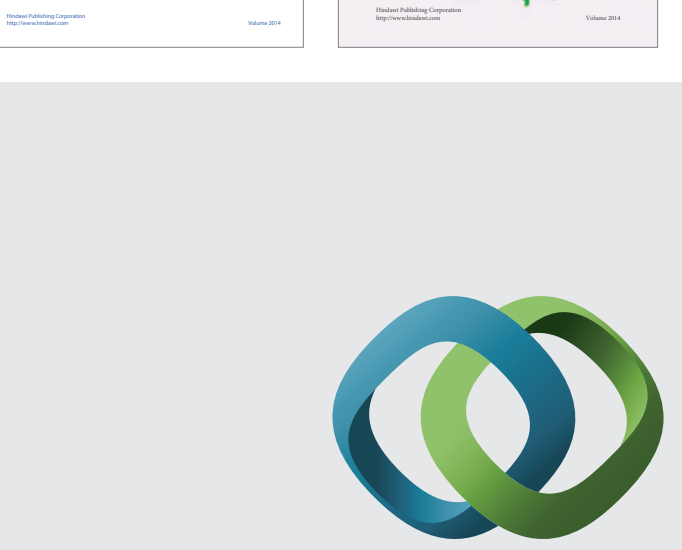

\section{Hindawi}

Submit your manuscripts at

http://www.hindawi.com
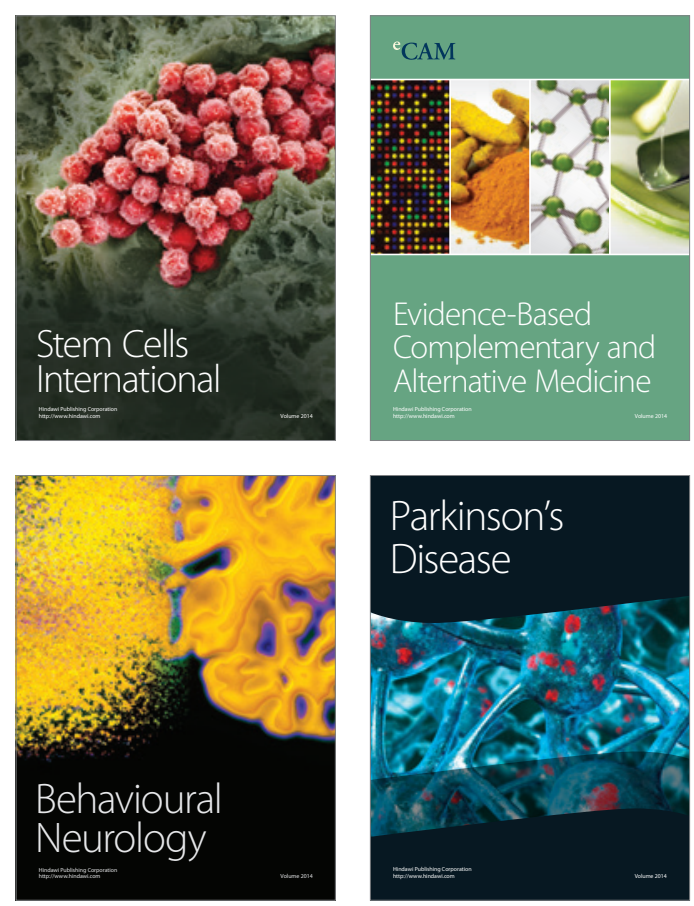

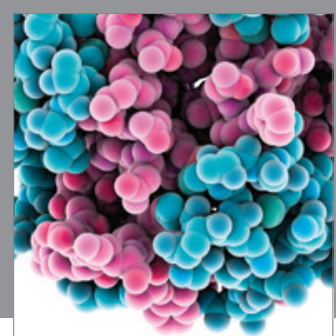

Journal of
Diabetes Research

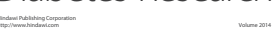

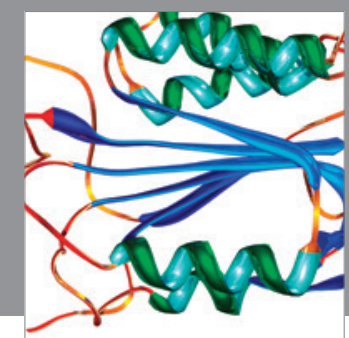

Disease Markers
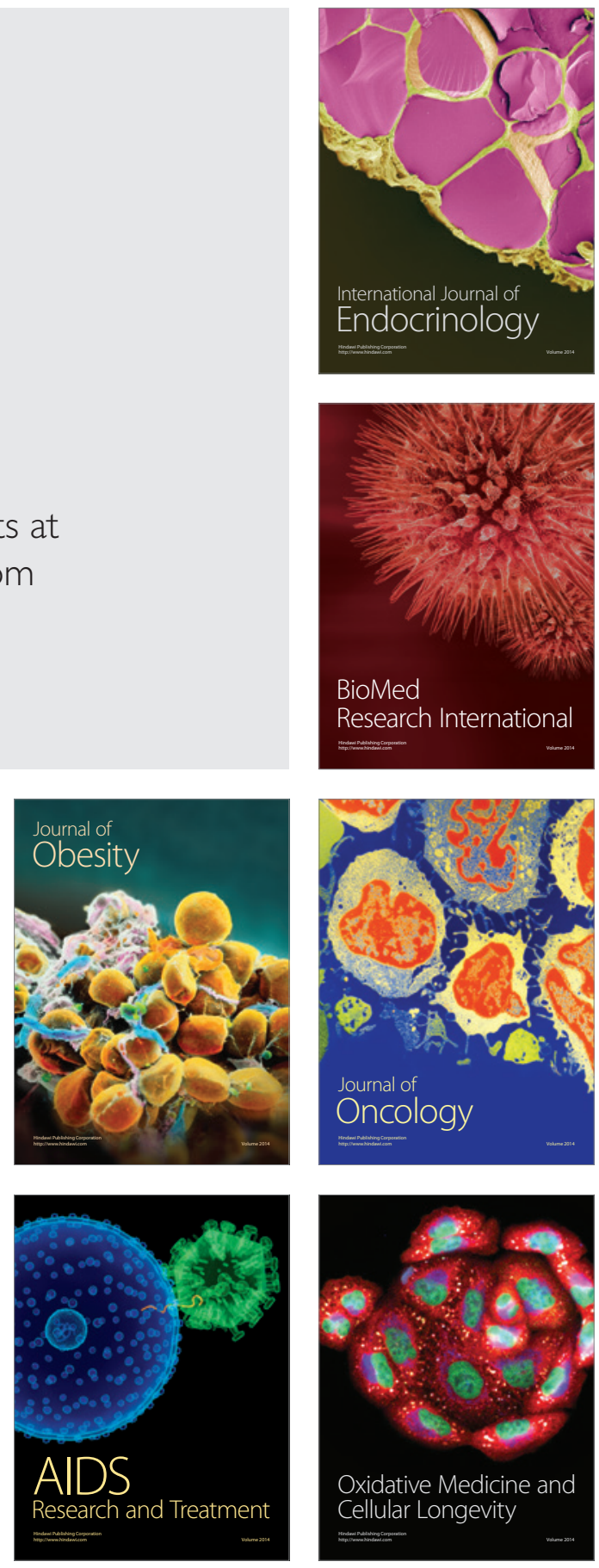